\title{
Editorial: Shifting from teacher education to child learning
}

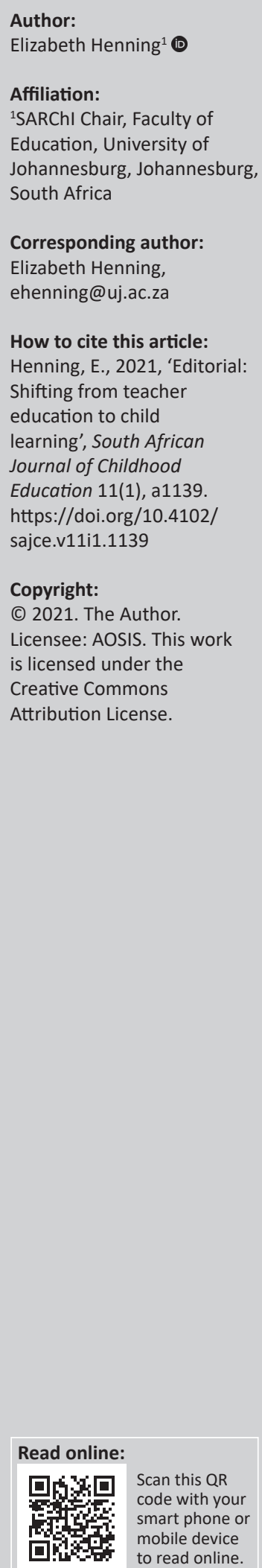

The articles in this volume continue to reflect a research theme that has been topical in all of its predecessors, since the founding of the journal in 2011: at the time, there was a renewed focus on teacher education for the foundation phase. Several of the authors wrote about the shortage of qualified teachers. This focus gradually changed to strategies that could increase the number of teachers and the number of BEd programmes for this all important phase of childhood education. Some of the research later shifted to classroom practice of early grade teachers and found that the Strengthening Foundation Phase Teacher Education Project (SFPTEP) of the Department of Higher Education and Training (DHET) had not only supplied more teachers for the national school system, but had emboldened some of the programmes at universities to design dynamic new degree programmes.

The SFPTEP paved the way for another country-wide development programme: the Primary Teacher Education (PrimTed) programme of the DHET was initiated to investigate the teacher education programmes at universities, with a specific focus on literacy and language and mathematics competence students in the programmes. The research momentum was maintained, and this is evident in the articles published in this journal. In Volume 11, close to half the articles report on teachers' work. Through the years, fewer studies about the learning of the children in the classrooms of our schools have been submitted, which raises a concern for the editorial board. The more we realise that teachers are pivotal in children's school learning, the more we need to know about the actual learning and progression of the young people who are entrusted to the teachers.

An example of a stronger focus on child learning is the publication of studies about learning difficulties, with authors who collaborate with schools as researchers of speech and language development and of learning support and other specialised professions. There is also a greater interest in the early learning and development of children before they enter school. We have recently published book review articles and reviews - all of which are highly recommended for future submission.

\section{Additional research topics for Volume 12}

For submissions in 2022, we would like to suggest a few areas:

- Studies of individual or group learner assessment, including tool design.

- Learning to read Science, technology, engineering, and mathematics (STEM) texts.

- Small-scale field experiments.

- Novel techniques and tools for investigating children's learning.

- Science learning in the early grades.

We thank all the reviewers who assisted us in rounding off Volume 11, and we invite readers and authors to kindly assist us to increase our reviewer pool. Do send the name and contact details of specialists in a field with which you are familiar to submissions@sajce.co.za. 